\title{
Is HoLEP the Only Gold Standard for Surgical Management of Benign Prostatic Hyperplasia?
}

\author{
Imran Mir, Jaydeep Date, Subodh Shivde, Prakash Patwardhan, Hrishikesh Deshmukh* \\ Deenanath Mangeshkar Hospital and Research Center, Pune, India \\ Email: drimranmir123@gmail.com, jaydeepdate@gmail.com, shivdes@gmail.com,drprakashurosurgeon@gmail.com, \\ *hrishideshmukh@yahoo.com
}

How to cite this paper: Mir, I., Date, J., Shivde, S., Patwardhan, P. and Deshmukh, H. (2017) Is HoLEP the Only Gold Standard for Surgical Management of Benign Prostatic Hyperplasia? Open Journal of Urology, 7, 159-165.

https://doi.org/10.4236/oju.2017.79019

Received: June 26, 2017

Accepted: September 25, 2017

Published: September 28, 2017

Copyright $\odot 2017$ by authors and Scientific Research Publishing Inc. This work is licensed under the Creative Commons Attribution International License (CC BY 4.0).

http://creativecommons.org/licenses/by/4.0/

\begin{abstract}
Purpose: HoLEP is now considered gold standard for the treatment of BPH allowing one stop surgical treatment for all sizes of glands. The Bipolar TURP carries some advantages of HoLEP like use of normal saline which allows resection for longer period of time. Additionally, there is less learning curve for bipolar TURP. We have conducted a prospective and retrospective observational study to compare and evaluate HoLEP and Bipolar TURP with respect to efficacy and surgical outcomes in our tertiary care hospital. Materials and methods: We have done a prospective and retrospective, comparative study from June 2012 to May 2014 on 200 Patients with BPH planned for surgery (fulfilling eligibility criteria), 100 in each group (HoLEP and Bipolar TURP). Results: We found that both techniques, HoLEP and Bipolar TURP, are safe and effective for treating patients with symptomatic BPH with similar functional outcomes and near similar complication rates. Conclusion: Bipolar TURP is very much comparable to HoLEP in term of efficacy and surgical outcomes. Larger multicentric studies with longer follow up data will be needed to further substantiate these findings.
\end{abstract}

\section{Keywords}

HoLEP, Bipolar TURP, Benign Prostatic Hyperplasia

\section{Introduction}

HoLEP is now an established modality of treatment for BPH. It is considered the gold standard for surgical management of BPH as it can be used in all patients of BPH even with large glands. The main advantage of HoLEP over TURP is use of normal saline for irrigation and hemostasis. This allows resection of larger gland for longer period of time with minimum bleeding. This is especially suitable for patients who are on anticoagulants or antiplatelet agents. But there is a learning 
curve to the technique of resection in HoLEP [1]. Also Laser in comparison with Bipolar Unit carries significant initial and maintenance cost.

The Bipolar TURP carries some advantages of HoLEP. Additionally the technique of bipolar resection is no differences from monopolar TURP [2].

But is Bipolar TURP comparable to HoLEP in terms of efficacy and functional outcomes?

We have conducted a study to gain insight into this issue with an aim to compare and evaluate HoLEP and Bipolar TURP in BPH (Benign prostatic Hyperplasia) patients in terms of their efficacy and surgical outcome in our tertiary care hospital.

\section{Materials and Method}

We have done a prospective and retrospective, comparative study from June 2012 to May 2014.

Sample size: 200 Patients with BPH planned for surgery (fulfilling eligibility criteria), 100 in each group (HoLEP and Bipolar TURP).

Patients have undergone either Bipolar TURP or HoLEP depending on choice made by surgeon and patient.

Bipolar transurethral prostate resection was performed using the bipolar unit (ERBE Model APC 2 (Germany)).

HoLEP was performed using the 550-micron end firing Laser fiber and a $\mathrm{Lu}$ menis Versa Pulse power suite (100 watts) transurethral morcellation was performed through $26 \mathrm{Fr}$ scope for evacuating tissue.

A $26 \mathrm{Fr}$ continuous flow resectoscope (Olympus and Storz for bipolar and Wolfe and Storz with modified bridge for HoLEP) was used.

Routine pre and postoperative measures were taken.

\subsection{Inclusion Criteria}

All clinically diagnosed BPH patients:

- Who had Obstructive flow on UFM (Uroflowmetry) (Q Max $<15 \mathrm{ml} / \mathrm{sec}$ )

- Significant PVR (post void residue) $(>75 \mathrm{ml}$ )

- Failed medical therapy (alpha blockers and Alpha reductase inhibitors)

- Presented with retention of urine/Failed voiding trial

\subsection{Exclusion Criteria}

- Patients with Ca Prostate

- $\mathrm{BPH}$ patients requiring additional procedures (e.g. Vesical Calculus)

- Invasive urothelial carcinoma

- Neurogenic bladders

- Previous prostate or urethral stricture surgery

\subsection{Statistical Methods}

Statistical analysis was done by descriptive statistics as mean, SD, range, propor- 
tions etc. $\mathrm{Z}$ test of difference between two means, Student's Paired " $\mathrm{t}$ " test and Chi-Square tests was applied for comparison and association between variables under study in both the groups. $\mathrm{p}<0.05$ is considered as significant. Statistical software namely SYSTAT version 12 was used.

\subsection{Various Parameters Studied Are}

Intraoperative parameters:

- Operative time

- Amount of irrigant used.

- Intra operative complications, if any

Postoperative parameters:

- Immediate complications like hematuria, retention, incontinence, UTI

- Duration of Catheter

- Hospital stay (Number of days)

- Blood loss and electrolyte changes

- Functional results-Flow rates/IPSS Score

Patients were followed up at 2 weeks, 3 months and 6 months postoperatively. Uroflometry (UFM) with post void residue (PVR) was done at $3 \& 6$ months follow up and any adverse effect was recorded.

Hospitalization cost of each patient was recorded and average cost for either group was calculated.

\section{Observations and Results}

On Comparison of Preoperative and Postoperative parameters, there was a significant decrease in IPSS, PVR and significant increase in Qmax from pre to postoperative state in both techniques of resection $(\mathrm{p}<0.001)$.

There was no significant decrease seen in Sodium and Potassium from pre to postoperative in either group (Table 1).

By applying " $Z$ " test of difference between two means there is a significant difference between mean values of Catheter time, Time of resection and Amount of irrigating fluid used when Bipolarand HOLEP Technique of resection compared

Table 1. Basic characteristic of patients in study.

\begin{tabular}{ccccc}
\hline \multirow{2}{*}{ Characteristics } & Preoperative & Postoperative & Student's Paired & “p” value \\
\cline { 2 - 4 } & Mean \pm SD & Mean \pm SD & & 0.001 \\
IPSS & $22.19 \pm 3.92$ & $9.49 \pm 3.147$ & 25.26 & 0.001 \\
Qmax (ml/sec) & $7.47 \pm 1.25$ & $15.72 \pm 6.76$ & 12.247 & 0.001 \\
PVR & $79.17 \pm 16.66$ & $11.26 \pm 11.23$ & 35.808 & 0.001 \\
Hb (g/dL) & $11.06 \pm 1.02$ & $10.66 \pm 1.09$ & 7.967 & 0.001 \\
PCV & $33.64 \pm 1.99$ & $32.41 \pm 1.62$ & 7.069 & 1.069 \\
NA (mmol/L) & $135.72 \pm 3.41$ & $135.35 \pm 3.46$ & 0.6491 & 0.1438 \\
K & $4.04 \pm 0.29$ & $4.02 \pm 0.34$ & 0.2589
\end{tabular}


Table 2. Comparison of intra operative and postoperative parameters in Bipolar and HOLEP Technique of resection.

\begin{tabular}{cccccc}
\hline \multirow{2}{*}{ Characteristics } & Bipolar $(\mathrm{n}=100)$ & HOLEP $(\mathrm{n}=100)$ & \multirow{3}{*}{ “Z” test value } & “p” value \\
\cline { 2 - 5 } & Mean \pm SD & Mean \pm SD & & 2.498 & 0.0133 \\
Catheter time (days) & $2.52 \pm 0.54$ & $2.34 \pm 0.53$ & $3.42 \pm 0.53$ & 1.867 & 0.0634 \\
Stay in hospital (days) & $3.58 \pm 0.67$ & $96.20 \pm 24.07$ & 9.350 & $<0.001$ \\
Time of resection (min) & $69.61 \pm 15.15$ & $18.76 \pm 2.56$ & 15.594 & 0.005 \\
Amount of irrigating fluid used (Lts) & $13.87 \pm 1.81$ & & & \\
\hline
\end{tabular}

each other, whereas no significant difference is seen in Stay in hospital (Table 2).

It is observed that, Time of resection and Amount of irrigating fluid used is higher and Catheter time (days), Stay in hospital was less in HOLEP as compared to Bipolar Technique of resection (Table 2).

By applying Chi-square test there is no significant association between immediate postoperative complications in Bipolar and HOLEP Technique of resection.

By applying Chi-square test there is no significant association between longterm postoperative complications at 6 months in Bipolar and HOLEP Technique of resection.

\section{Discussion}

In our study, we compared both HoLEP and bipolar resection of the prostate, trying to find out the advantages of each technique over the other.

Although TURP has been considered the gold standard surgical therapy for patients with BPH for many years, many new endoscopic technologies have been introduced to treat BPH. ${ }^{10}$ The new technologies Bipolar TURP and HoLEP are widely used and have been proposed to replace TURP as the new reference standard. However to date short term and long term outcome studies of these two techniques have been scanty.

Ho and colleagues [3] in a randomized study compared both the bipolar and monopolar resection of the prostate; they showed a significant advantage of the bipolar approach regarding the occurrence of TUR absorption syndrome (0 of 48 bipolar vs. 2 of 52 monopolar patients undergoing resection) and hemostasis.

In our study there was no TUR syndrome reported in either groups. There was no statistically significant difference in hemorrhage in two groups (Table 3 ).

Chen and colleagues [4] in a randomized controlled trial concluded that HoLEP was superior and proposed that this should be considered the new gold standard operative procedure for BPE. Patients in the HoLEP group had less blood loss, shorter bladder irrigation times, and a reduced hospital stay. There were no significant differences in IPSS, QoL, and Qmax with 2 years of follow up, and there were no differences in complications.

In contrast, in a second randomized controlled trial of bipolar Fayed et al. [5] 
Table 3. Association between immediate postoperative complications in Bipolar and HOLEP Technique of resection $(n=100)$.

\begin{tabular}{cccc}
\hline $\begin{array}{c}\text { Immediate postoperative } \\
\text { complications }\end{array}$ & $\begin{array}{c}\text { Bipolar } \\
(\mathrm{n}=100)\end{array}$ & $\begin{array}{c}\text { HOLEP } \\
(\mathbf{n}=100)\end{array}$ & P-value \\
\hline Haemorrhage & $4(4 \%)$ & $1(1 \%)$ & 0.365 \\
Urinary tract Infections & $3(3 \%)$ & $1(1 \%)$ & 0.613 \\
Irritative symptoms & $6(6 \%)$ & $3(3 \%)$ & 0.505 \\
Incontinence & $5(5 \%)$ & $8(8 \%)$ & 0.566 \\
Failure to void & $13(13 \%)$ & $11(11 \%)$ & 0.827 \\
& & &
\end{tabular}

Table 4. Association between Long term/postoperative complications at 6 months in Bipolar and HOLEP Technique of resection $(n=100)$.

\begin{tabular}{cccc}
\hline $\begin{array}{c}\text { Long term postoperative } \\
\text { complications at 6 months }\end{array}$ & $\begin{array}{c}\text { Bipolar } \\
(\mathbf{n}=100)\end{array}$ & $\begin{array}{c}\text { HOLEP } \\
(\mathbf{n}=100)\end{array}$ & P-value \\
\hline Stricture & $8(8 \%)$ & $6(6 \%)$ & 0.781 \\
Incontinence & $2(2 \%)$ & $4(4 \%)$ & 0.678 \\
BNC (bladder neck contracture) & 0 & $3(3 \%)$ & \\
\hline
\end{tabular}

Table 5. Hospitalization and equipment cost Conversion (One USD = 60 INR).

\begin{tabular}{ccc}
\hline & Bipolar & HoLEP \\
\hline $\begin{array}{c}\text { Approximate Hospitalisation } \\
\text { cost in INR(USD) }\end{array}$ & $80,000-110,000(1333-1833)$ & $100,000-125,000(1666-2083)$ \\
Approximate Cost of equipment & $1,200,000(20,000)$ & $8,000,000(133,333)$ \\
\hline
\end{tabular}

concluded that the blood loss, complications, and outcomes were not statistically different between the two groups. They favored bipolar resection due to the high costs of the holmium laser. They also considered that the resection technique was more familiar to urologists, was easier to master, and avoided the difficulties of the learning curve, and that the equipment for bipolar resection was readily available in most urological theatres.

In our study there was no significant difference in immediate and long term post op complications in two groups (Table 2).

However catheter time was significantly less and operative time and amount of irrigation fluid used was significantly high in HoLEP group (Table 1, Table 2 \& Table 4).

In a systematic search on Medline by Narmada P Gupta et al. [6] stated that Bipolar TURP, HoLEP provide equivalent outcomes for large prostate adenoma $(>60 \mathrm{~g})$ Bipolar TURP is an attractive option with minimal learning curves and equivalent short term durability.

Our study of 200 patients further support this assertion.

Fumado L et al. [7] compared the impact of the learning curves of Bipolar TURP and HoLEP by two self-taught urologist at $1 \mathrm{yr}$. They opined that Bipolar TURP is faster and safer than HoLEP in the learning curve period with equiva- 
lent functional outcomes. The complication rates of HoLEP should be taken into mind before considering the introduction of this technique. Training under mentorship is recommended.

Based on our small study we can say that bipolar TURP is technically similar to monopolar TURP hence learning curve is significantly small.

Bipolar TURP is equally safe compared to HoLEP as there was no significant difference in the immediate and long term complications, in our study (Table 4).

\section{Conclusions}

- Both techniques, HoLEP and Bipolar TURP, are safe and effective for treating patients with symptomatic BPH with similar functional outcomes and near similar complication rates.

- The hospitalization cost is approximately $20 \%-30 \%$ less with Bipolar TURP. The equipment cost for Bipolar TURP is approximately eight times less when compares to Holmium Laser (Table 5).

- HoLEP is associated with longer operative time and has a long learning curve.

- Bipolar TURP is an attractive option with some advantages of LASER with small learning curve, less cost and proven short term results.

- Larger multicentric studies with longer follow up data will be needed to further substantiate these findings.

- Finally, it will be surgeon's experience with the technique and patient's choice that will decide which method will prevail in future.

\section{Limitations of Study}

Randomized control study with blinding was not possible as surgery is an informed decision.

\section{Conflict of Interest}

None.

Approval of the Ethical committee of the hospital has been taken prior to the study.

\section{References}

[1] Gilling, P.J., Wilson, L.C., King, C.J., Westenberg, A.M., Frampton, C.M. and Fraundorfer, M.R. (2012) Long-Term Results of a Randomized Trial Comparing Holmium Laser Enucleation of the Prostate and Transurethral Resection of the Prostate: Results at 7 Years. BJU International, 109, 408-411. https://doi.org/10.1111/j.1464-410X.2011.10359.x

[2] Mamoulakis, C., Trompetter, M. and de la Rosette, J. (2009) Bipolar Transurethral Resection of the Prostate: The "Golden Standard" Reclaims Its Leading Position. Current Opinion in Urology, 19, 26-32. https://doi.org/10.1097/MOU.0b013e328320a61a 
[3] Ho, H.S., Yip, S.K., Lim, K.B., et al. (2007) A Prospective Randomized Study Comparing Monopolar and Bipolar Transurethral Resection of Prostate Using Transurethral Resection in Saline (TURIS) System. European Urology, 52, 517-522. https://doi.org/10.1016/j.eururo.2007.03.038

[4] Chen, Y., Chen, Q., Wang, Z., Peng, Y.B., Ma, L.M., Zheng, D.C., et al. (2013) A Prospective, Randomized Clinical Trial Comparing Plasmakinetic Resection of the Prostate with Holmium Laser Enucleation of the Prostate Based on a 2-Year Followup. The Journal of Urology, 189, 217-222. https://doi.org/10.1016/j.juro.2012.08.087

[5] Fayad, A.S., Sheikh, M.G.E., Zakaria, T., Elfottoh, H.A. and Alsergany, R. (2011) Holmium Laser Enucleation versus Bipolar Resection of the Prostate: A Prospective Randomized Study. Which to Choose? Journal of Endourology, 25, 1347. https://doi.org/10.1089/end.2011.0059

[6] Gupta, N.P. and Nayyar, R. (2013) Management of Large Prostatic Adenoma: Lasers versus Bipolar Transurethral Resection of Prostate. Indian Journal of Urology, 29, 225-235. https://doi.org/10.4103/0970-1591.117288

[7] Fumado, L., Pino, L., Lorente, J.A. and Rijo, E. (2011) Bipolar TURP vs. HoLEP Selective Improvement After 1 Yr Follow Up .Comparative Analysis of Two Learning Curves. World Congress of Endourology, Kyoto.

Submit or recommend next manuscript to SCIRP and we will provide best service for you:

Accepting pre-submission inquiries through Email, Facebook, LinkedIn, Twitter, etc. A wide selection of journals (inclusive of 9 subjects, more than 200 journals) Providing 24-hour high-quality service User-friendly online submission system Fair and swift peer-review system Efficient typesetting and proofreading procedure Display of the result of downloads and visits, as well as the number of cited articles Maximum dissemination of your research work

Submit your manuscript at: http://papersubmission.scirp.org/ Or contact oju@scirp.org 